Research Article

\title{
The Antioxidant Polysaccharide from Semiaquilegia adoxoides (DC.) Makino Adjusts the Immune Response of Mice Infected by Bacteria
}

\author{
Yunqiao Yang ${ }^{D},{ }^{1}$ Lei Guo, ${ }^{2}$ Kinza Tariq, ${ }^{1}$ Weiyu Zhang, ${ }^{1}$ Chong Li, ${ }^{1}$ \\ Fareed Qamar Memon, ${ }^{1}$ Beibei Chai, ${ }^{1}$ Zheng Li, ${ }^{1}$ Junying Sun, ${ }^{1}$ Yunru Chen, ${ }^{1}$ Geyin Zhang, \\ Qinmei Li, ${ }^{1}$ Shuaiyang Wang, ${ }^{1}$ Lizhen Wang, ${ }^{1}$ Chongbo Lai, ${ }^{1}$ Mingsheng Jiang, \\ and Hongbin Si $\mathbb{D}^{1}$
}

${ }^{1}$ College of Animal Sciences and Technology, Guangxi University, Nanning, China

${ }^{2}$ College of Bioscience and Biotechnology, Yangzhou University, Yangzhou, China

Correspondence should be addressed to Hongbin Si; shb2009@gxu.edu.cn

Received 7 May 2019; Revised 11 September 2019; Accepted 24 January 2020; Published 19 February 2020

Academic Editor: Barbara Romano

Copyright ( 92020 Yunqiao Yang et al. This is an open access article distributed under the Creative Commons Attribution License, which permits unrestricted use, distribution, and reproduction in any medium, provided the original work is properly cited.

Semiaquilegia adoxoides (DC.) Makino is a herbal medicine and it is recorded that its water extract can be used to treat acute diseases caused by bacterial infections. In order to understand the polysaccharide of Semiaquilegia adoxoides (DC.) Makino (SMP), FT-IR and HPLC methods were performed to determine the basic chemical structure and monosaccharide compositions of SMP. The antioxidant capacity of SMP was analyzed by monitoring both the scavenging rate of DPPH and ABTS free radical. To investigate the effects of SMP on the acute bacterial disease, minimum inhibitory concentrations (MICs) of SMP on E. coli or S. aureus were detected; meanwhile, mice were administrated with SMP for 7 days and then infected with E. coli or S. aureus, and the parameters were measured at the $9^{\text {th }}$ day. Results showed that SMP was a furanose which was mainly composed of glucose (60.3\%) and had certain antioxidant activities. Both MIC values of SMP on E. coli and S. aureus were $250 \mathrm{ml} / \mathrm{mL}$, which means that SMP has no direct antibacterial effects. The mice experiments revealed that SMP had potential effects on immunomodulatory by reducing WBC and the expression of serum IL-1, IL-6, and TNF- $\alpha$ and increasing IgM of $E$. coli or $S$. aureus infected mice. These findings supported the effect of Semiaquilegia adoxoides (DC.) Makino in folk use with scientific evidence.

\section{Introduction}

Our body is surrounded by microbes, including Escherichia coli (E. coli), Staphylococcus aureus (S. aureus), and other pathogenic microorganisms. These bacteria can cause nosocomial and farm infection which can result in serious infections [1]. In recent years, the abuse of antibiotics in the treatment of bacterial diseases has led to the emergence of a variety of antibiotic-resistant bacteria, and the search for alternatives has become an urgent need. Immune-related cells block the spread and infection of pathogenic bacteria, but the components which are released by bacteria can also influence the immune system. Therefore, the use of special compounds to kill bacteria and/or enhance the body's immune system can help to deal with the infection by bacteria [2]
Semiaquilegia adoxoides (DC.) Makino (Ranunculaceae) (S. Makino) is a medicinal plant and it is the only member of Semiaquilegia genus which distribute in Japan and Subtropical Region of the Yangtze River Basin in China [3]. Pharmacological research indicated that the n-butanol extract of S. Makino protects human lens epithelial cells in oxidative stress which was induced by hydrogen peroxide [4], and the ethanol extraction of S. Makino has certain anticancer activity [5]. According to the documentation in ancient China, the powers or aqueous extractions of $S$. Makino have been widely used in the treatment of furuncle swelling, tonsillitis, and mammary abscess which are often associated with $S$. aureus and E. coli in clinical infection according to modern medical theory $[5,6]$. Plant polysaccharides are soluble in water and have a relatively high 
content in water extraction, and the multiple biological functions of polysaccharides from nature plants were well recorded in recent literatures, such as antibacterial [7], antioxidant [8], antitumor [9], and immune activities [10]. However, few reports covered the basic structure, antioxidant, and biological activities of polysaccharides of $S$. Makino.

The purposes of this work were to evaluate (1) the antioxidative effects of $S$. Makino polysaccharides (SMP) by DPPH and ABTS methods, (2) the inhibitory effect of SMP on the growth of $S$. aureus or E. coli by serial-dilution culture method, and (3) the immunomodulatory activity of SMP on $S$. aureus or E. coli infected mice by mortality and cytokine production in serum. Additionally, the monosaccharide compositions and Fourier-transform infrared spectroscopy (FT-IR) analysis of SMP were also conducted.

\section{Materials and Methods}

2.1. Materials and Reagents. Standard monosaccharide samples were purchased from Sigma Chemicals Company (St. Louis, USA). ELISA kits for assaying the IL-1, IL-6, TNF$\alpha$, and IgM in serum were purchased from Shanghai E-research Company (Shanghai, China). Amikacin and vancomycin were supplied by our laboratory. All other reagents and chemicals were of analytical grade and purchased from local chemical suppliers.

2.2. Extraction. Semiaquilegia adoxoides (DC.) Makino (Ranunculaceae) (500 g) were grounded into powder and macerated with $1000 \mathrm{ml}$ anhydrous ethanol overnight for the removal of lipids. The precipitates were collected and heated with $2000 \mathrm{ml}$ double-distilled water $\left(\mathrm{ddH}_{2} \mathrm{O}\right)$ at $85^{\circ} \mathrm{C}$ for $3 \mathrm{~h}$ for 3 times. All the extractions of S. Makino were filtered and then centrifuged at $9000 \mathrm{rpm}$ for $5 \mathrm{~min}$. The supernatants were combined and concentrated at $85^{\circ} \mathrm{C}$ to $500 \mathrm{ml}$ and precipitated with three volumes of anhydrous ethanol (75\%, $\mathrm{v} / \mathrm{v}$ ) overnight at $4^{\circ} \mathrm{C}$ and then centrifuged again as above. The precipitate was dissolved in $\mathrm{ddH}_{2} \mathrm{O}$ and then after 7 times of deproteinization by Sevag method [11], the precipitation process was repeated with anhydrous ethanol $(95 \%, v / v)$ three times. The final precipitate was washed consecutively with acetone and ether and then freeze-dried to obtain the SMP. The content of polysaccharides in $S$. Makino was determined by phenol sulphuric acid assay [12].

\subsection{Fourier-Transform Infrared Spectroscopy (FT-IR)} Analysis. $2.0 \mathrm{mg}$ SMP sample was mixed with $200 \mathrm{mg} \mathrm{KBr}$. After grinding and pressing into $\mathrm{KBr}$ pellet, scanning was performed between the ranges of $4000 \mathrm{~cm}^{-1}$ to $400 \mathrm{~cm}^{-1}$ with a resolution of $4 \mathrm{~cm}^{-1}$.

2.4. Analysis of SMP Monosaccharide Composition. The monosaccharide composition of SMP was detected by highperformance liquid chromatography (HPLC) after acid hydrolysis according to the report [13]. Briefly, the SMP sample $(10 \mathrm{mg})$ was hydrolyzed with trifluoroacetic acid
(TFA, $2 \mathrm{M}, 3 \mathrm{~mL}$ ) at $121^{\circ} \mathrm{C}$ for $2 \mathrm{~h}$ in a tube. Residual TFA was removed with a QGC-12T nitrogen blowing instrument at $50^{\circ} \mathrm{C}$. The hydrolyzed samples were then redissolved in $\mathrm{ddH}_{2} \mathrm{O}$ and analyzed with ICS 5000 ion chromatography (Dionex, Sunnyvale, CA) with a CarboPac PA20 analytic column $(150 \mathrm{~mm} \times 3 \mathrm{~mm}$ inner diameter $)$ and a pulsed amperometric detector. The mobile phase consisted of $250 \mathrm{mM} \mathrm{NaOH}(2 \%)$ and water (98\%) at a flow rate of $0.5 \mathrm{~mL} \cdot \mathrm{min}^{-1}$.

2.5. DPPH Radical Scavenging Assay. $3.0 \mathrm{ml}$ sample solution with various concentrations $(0.3-5 \mathrm{mg} / \mathrm{mL})$ was mixed with $2.0 \mathrm{ml} \mathrm{DPPH}$ solution $(0.2 \mathrm{mM}$, dissolved in ethanol). After being incubated for $30 \mathrm{~min}$ in the dark at $25^{\circ} \mathrm{C}$, the absorbance of the mixture against blank was determined at $520 \mathrm{~nm}$. The DPPH radical scavenging activity was calculated as the percentage of inhibition according to the following equation:

$$
=\left(1-\frac{A_{\mathrm{s}}-A_{\mathrm{s} 0}}{A_{0}}\right) \times 100 \% .
$$

In this equation, $A_{0}$ is the absorbance of a blank treatment group, $A_{\mathrm{s}}$ is the absorbance of a sample treatment group, and $A_{\mathrm{s} 0}$ is the absorbance of a sample background. All measurements were performed in triplicate and ascorbic acid (Vitamin C) was used as a positive control.

2.6. ABTS Radical Scavenging Assay. The $\mathrm{ABTS}^{\bullet+}$ was prepared by mixing an ABTS stock solution ( $7 \mathrm{mM}$ in water) with $2.45 \mathrm{mM}$ potassium persulfate. This mixture was kept still for $16 \mathrm{~h}$ at $25^{\circ} \mathrm{C}$ in the dark. The $\mathrm{ABTS}^{\bullet+}$ working solution was obtained by diluting the stock solution in methanol to an absorbance of $0.7 \pm 0.10$ at $747 \mathrm{~nm} .0 .5 \mathrm{ml}$ diluted sample was added to $5.0 \mathrm{ml} \mathrm{ABTS}{ }^{\bullet+}$ working solution and mixed thoroughly. The reaction mixture was kept at $25^{\circ} \mathrm{C}$ in the dark for $6 \mathrm{~min}$, and the absorbance was recorded at $747 \mathrm{~nm}$. ABTS radical scavenging activity was calculated as follows:

$$
=\left(1-\frac{A_{\mathrm{s}}-A_{\mathrm{s} 0}}{A_{0}}\right) \times 100 \% \text {. }
$$

In this equation, $A_{0}$ is the absorbance of a blank treatment group, $A_{\mathrm{s}}$ is the absorbance of a sample treatment group, and $A_{\mathrm{s} 0}$ is the absorbance of a sample background. All measurements were performed in triplicate and ascorbic acid (Vitamin C) was used as a positive control.

2.7. Animals and Bacterial Strains. Young adult males (average weight $18-22 \mathrm{~g}$ ) and females (average weight 18-22 g) SPF mice were purchased from Guangxi Medical University Laboratory Animal Center. The mice were kept in wellventilated cages in the animal houses of Guangxi University and provided with sterilized water and complete formula feed and housed in a rodent facility at $25^{\circ} \mathrm{C}$ with a $12 \mathrm{~h}$ lightdark cycle for acclimatization. All procedures involving animals and their care used were approved by the Ethics 
Committee of Guangxi University. Experiments were started after the mice acclimating for a week.

E. coli and S. aureus were identified and provided by our laboratory.

2.8. Determination of Minimum Inhibitory Concentrations (MICs). MIC values of SMP against 2 bacterial species were determined by the serial-dilution culture method.

TSB was used as the incubation medium. The SMP solution was serially diluted by TSB. All tubes $(13 \times 100 \mathrm{~mm})$ contained $1.75 \mathrm{ml}$ SMP solution and $1.75 \mathrm{ml}$ of diluted bacterial inoculum (approximately $10^{4} \mathrm{CFU} / \mathrm{ml}$ ), with a final concentration of SMP solution of $0.49,0.98,1.95,3.91,7.81$, $15.63,31.25,62.50,125.00,250.00$, and $500.00 \mathrm{mg} / \mathrm{ml}$. After incubation at $37^{\circ} \mathrm{C}$ for $24 \mathrm{~h}$, MICs were measured by visual inspection of the turbidity of broth in tubes [14]. Amikacin was used as a positive control drug of anti-E. coli and vancomycin was used as a positive anti-S. aureus control. All assays were carried out in triplicate.

2.9. Experimental Design. 168 mice were randomly divided into seven groups including the control group, E. coli group, $E$. coli + amikacin group, E. coli $+\mathrm{SMP}$ group, $S$. aureus group, $S$. aureus + vancomycin group, and S. aureus + SMP group. Each group contained 12 females and 12 males. Each mouse in the E. coli + SMP group and $S$. aureus + SMP group was administrated by gavage with $0.1 \mathrm{~mL} / 10 \mathrm{~g}$ of SMP $(1 \mathrm{~g} / \mathrm{mL})$ one time every day, while mice in the other groups were orally administered with the same volume of $\mathrm{ddH}_{2} \mathrm{O}$. On the $7^{\text {th }}$ day after treatment with SMP, each mouse in the $E$. coli group, $E$. coli + amikacin group, and E. coli + SMP group was intraperitoneally injected with $0.10 \mathrm{~mL} / 10 \mathrm{~g}$ of $2 \times 10^{8} \mathrm{CFU} / \mathrm{ml}$ (LD50) of E. coli. At the same time, in the $S$. aureus group, $S$. aureus + vancomycin group, and $S$. aureus + SMP group, each mouse was intraperitoneally injected with $0.10 \mathrm{~mL} / 10 \mathrm{~g}$ of $3.7 \times 10^{6} \mathrm{CFU} / \mathrm{ml}$ (LD50) of $S$. aureus, while mice in the control group were intraperitoneally injected with the same volume of sterile PBS. Mice in the E. coli + amikacin group or $S$. aureus + vancomycin group were infected with $E$. coli or $S$. aureus and subcutaneously injected with amikacin $(60 \mathrm{mg} / \mathrm{kg})$ or vancomycin $(50 \mathrm{mg} / \mathrm{kg})$ at 5 hours after infection, respectively, which means that these groups were for positive drug controls. The number of deaths in each group of mice was recorded after mice were injected with bacteria. After 42 hours of infection, mice were starved for food and water for 6 hours before being executed. Blood and serum were collected in each animal. In other words, the polysaccharides treated group was administered with SMP for 9 days and all the trials lasted for 9 days.

2.10. White Blood Cell Count. Blood samples were collected into an EDTA tube for white blood cell (WBC) counts.

2.11. Analysis of Cytokine Production and Antibody in the Serum. Analysis of IL-1, IL-6, TNF- $\alpha$, and IgM in serum samples was performed according to the commercially ELISA kit manual.
2.12. Statistical Analysis. Statistical analysis was performed using SPSS (version 16.0, SPSS Inc., Chicago, IL, USA). Differences between the mortality rates were analyzed using the chi-square test. For DPPH and ABTS radical scavenging activity rates, enumeration of WBC, and serum IL-1, IL-6, TNF- $\alpha$, and IgM levels, differences between groups were analyzed using one-way analysis of variance (ANOVA) followed by post hoc analysis using Tukey test. Differences were considered significant at $P<0.05$.

\section{Results and Discussion}

3.1. DPPH and ABTS Radical Scavenging Activity. DPPH method is often used; meanwhile, it is an easy and rapid way to evaluate the free radical scavenging activity of polysaccharide and other natural compounds, as DPPH radicals are stable at room temperature but can be easily scavenged by antioxidants [15]. As shown in Figure 1(a), the SMP and positive control (Vitamin C) showed scavenged activities on DPPH radicals. $84.1 \%$ of DPPH scavenging efficiency was obtained at a concentration of $10 \mathrm{mg} / \mathrm{ml}$ of SMP, which showed a significant difference with that of Vitamin $\mathrm{C}$ $(P=0.002)$. This DPPH scavenging activity was also correlated with the increasing concentrations of SMP.

The assay of ABTS radical cation $\left(\mathrm{ABTS}^{+}\right)$scavenging is also a commonly applied way to measure the antioxidant activity of natural products [16]. ABTS radical scavenging activities of SMP were determined and the results are shown in Figure 1(b). The highest scavenging ratios generated by $10 \mathrm{mg} / \mathrm{ml}$ of SMP were referred to be $74.8 \%$, which was significantly lower than that of Vitamin $C(P=0.003)$. The ABTS radical scavenging activities of SMP were also increased in a concentration-dependent manner and the positive control (Vitamin $\mathrm{C}$ ) also had higher radical scavenging activities than that of SMP, which was over $97 \%$ at all concentrations and similar to the results of DPPH in Figure 1(a). This result also confirmed the positive correlation between DPPH and ABTS radical scavenging assay on antioxidant activity [17].

However, it is difficult to explain the scavenging mechanisms of polysaccharides on DPPH and ABTS radicals as the complexity of constituent and structure of this carbohydrate.

3.2. FT-IR Spectroscopy Analysis of SMP. FT-IR is widely used by most researchers for the determination of the molecular structure of polysaccharides and the investigation of complex polymers [18]. The SMP was scanned by infrared spectroscopy and the results were shown in Figure 2. SMP showed typical absorption peaks of polysaccharides. A broad and intense peak nearby $3302 \mathrm{~cm}^{-1}$ was due to the $\mathrm{O}-\mathrm{H}$ stretching vibration in polysaccharide [19]. The bands centered around $2934 \mathrm{~cm}^{-1}$ were the characteristic absorption of C-H of sugar ring [20]. It is possible that the absorption peak of $1652 \mathrm{~cm}^{-1}$ was the characteristic absorption of carbonyl, aldehyde, or carboxyl groups [21]. The $\mathrm{C}-\mathrm{H}$ deformation vibration of the sugar ring was observed ranging from 1200 to $1400 \mathrm{~cm}^{-1}$ [22]. The perks ranging 


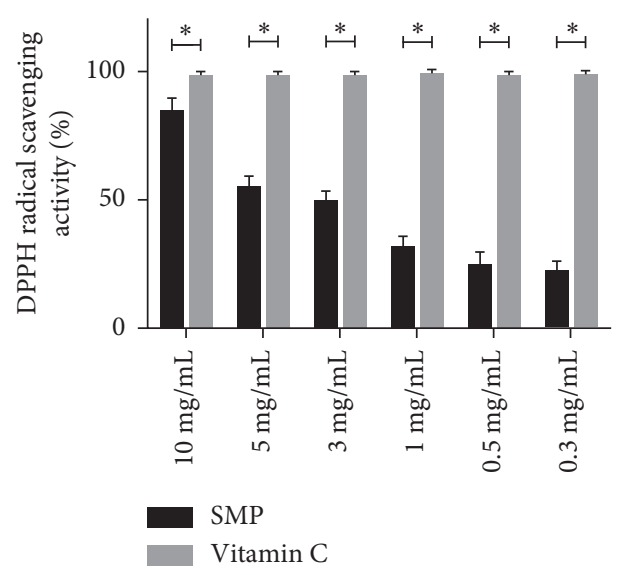

(a)

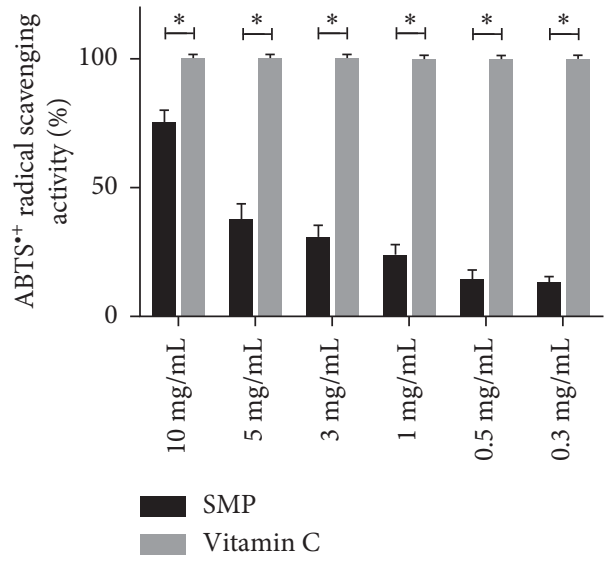

(b)

FIgURE 1: DPPH and ABTS radical scavenging activity of SMP. (a) DPPH radicals and (b) ABTS radicals. Note: ${ }^{*} P<0.05$.

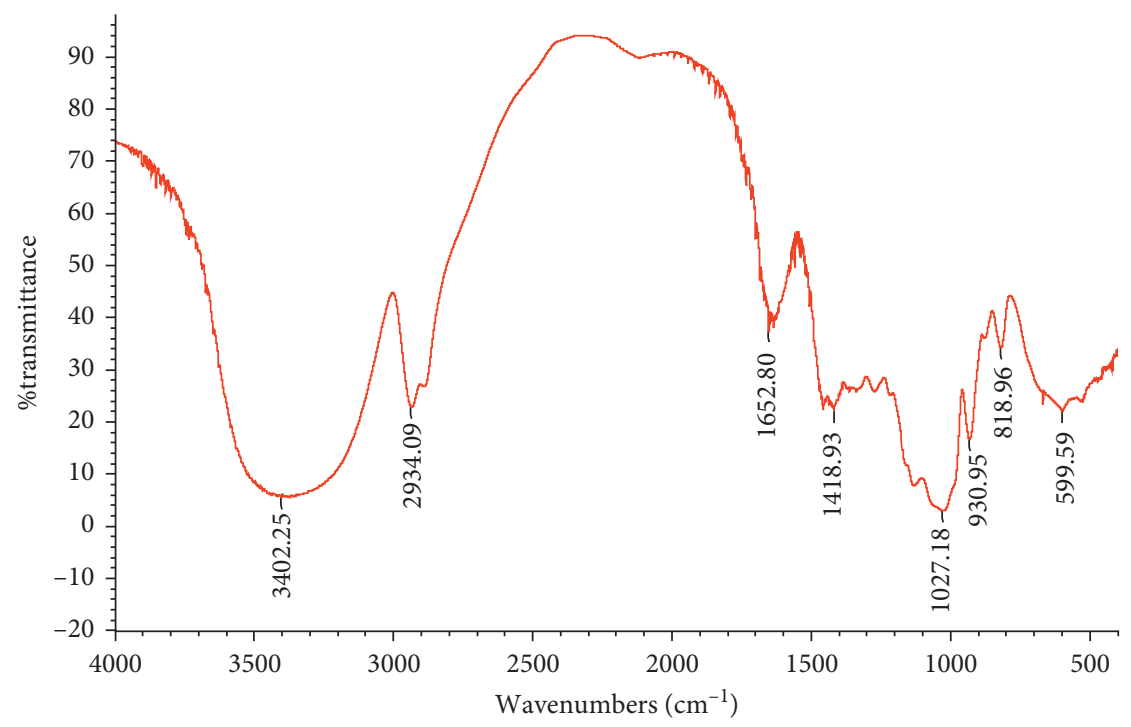

FIGURE 2: FT-IR spectra of SMP.

from 1000 to $1200 \mathrm{~cm}^{-1}$ were ascribed to the absorption of the pyranose ring [23]. The results indicated that SPM is a furanose.

3.3. Polysaccharide Content and Monosaccharides Composition of SMP. The total sugar content of SMP was estimated to be $92.37 \%$, and according to the HPLC results, SMP was composed of Glc (60.3\%), Gal (15.4\%), Xyl (11.1\%), GalA (9.3\%), and Man (3.9\%) (Figure 3).

3.4. MICs Assay. As shown in Table 1, positive drugs have obvious inhibitory effects on specific bacteria. The MIC value of amikacin against E. coli was $32 \mu \mathrm{g} / \mathrm{ml}$ and vancomycin against S. aureus was $16 \mu \mathrm{g} / \mathrm{ml}$. However, MICs of SMP against $E$. coli and $S$. aureus were both determined to be $250 \mathrm{mg} / \mathrm{ml}$. This inhibitory concentration of SMP on E. coli and $S$. aureus is too high to be used in practical situations; therefore, we can conclude that SMP has no direct inhibitory effect on these two bacteria.

3.5. The Mortality, Enumeration of WBC, Serum IL-1, IL-6, $T N F-\alpha$, and IgM. In this animal experiment section, we found that gender did not make any difference in all the mortality, WBC, serum IL-1, IL-6, TNF- $\alpha$, and IgM data (data not shown).

The number of survivors and mortality data for each group were shown in Table 2. As this part of the trial focused on the effect of different treatment methods on the mortality of bacteria-infected mice, the blank control group (uninfected and without intervention) was not involved in the comparison. Crosstabs analyses showed that although it is not as significant as the effects of positive drugs $(P=0.025$ of $E$. coli infected groups and $P=0.003$ of $S$. aureus infected groups), it is easy to find that SMP can reduce the deaths of mice which was infected with $E$. coli or $S$. aureus. 


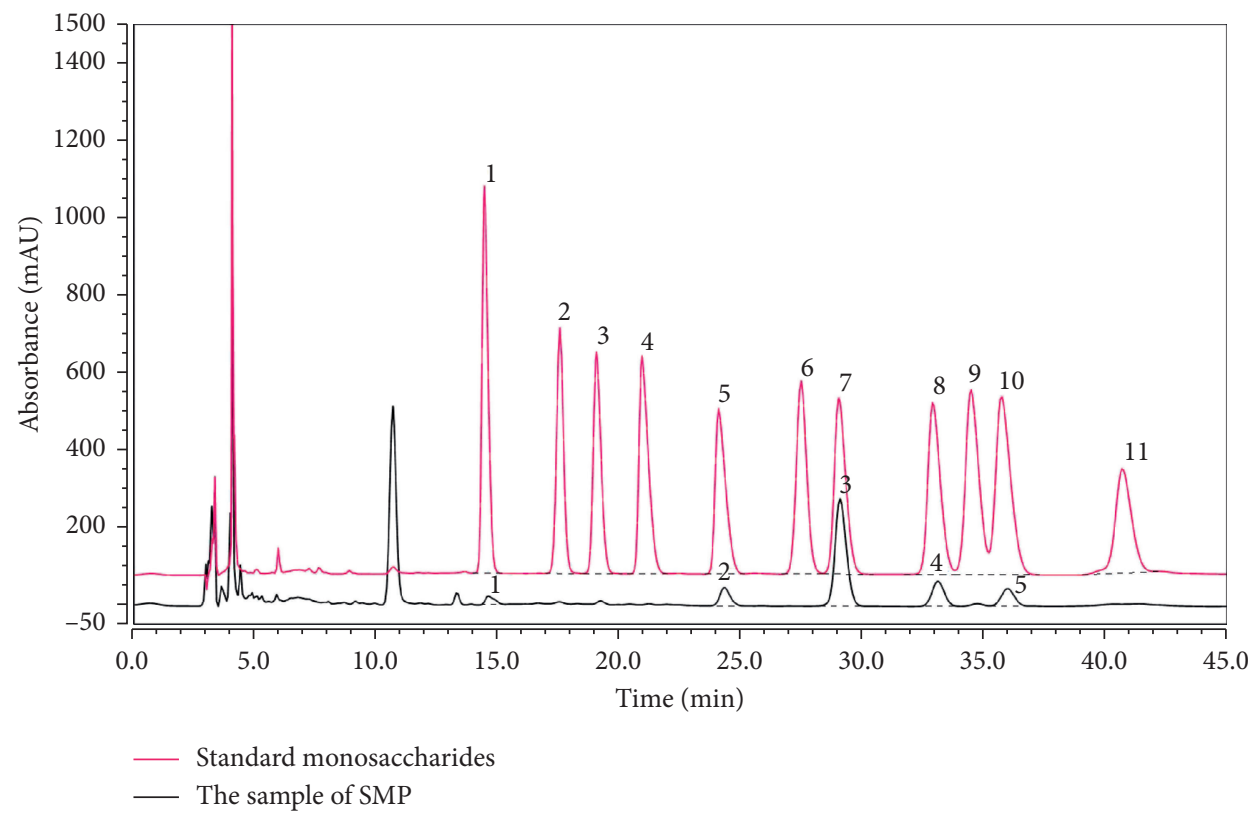

FIGURE 3: Monosaccharides compositions analysis of STP by HPLC precolumn derivatization. 1: Man, 2: GlcN, 3: Rha, 4: GlcA, 5: GalA, 6: GalN, 7: Glc, 8: Gal, 9: ara, 10: Xyl, and 11: Fuc.

TABle 1: The MIC values of different drugs for E. coli and S. aureus.

\begin{tabular}{lcc}
\hline & E. coli & S. aureus \\
\hline Amikacin $(\mu \mathrm{g} / \mathrm{ml})$ & 32 & - \\
Vancomycin $(\mu \mathrm{g} / \mathrm{ml})$ & - & 16 \\
SMP $(\mathrm{mg} / \mathrm{ml})$ & 250 & 250
\end{tabular}

The body expends a lot of energy when fighting with infection. Although SMP has no direct antibacterial activity, it belongs to the carbohydrate which can provide energy for the body. It has been confirmed that the infection of E. coli or $S$. aureus can cause an apparent oxidative reaction in the body [24, 25]. According to the above results, SMP can improve the survival rate of $E$. coli or $S$. aureus infected mice as SMP has certain energy providing and antioxidant activity.

The results of WBC count were measured by a routine blood test. According to the test report, the reference range of WBC is 0.80 to 10.60 . As shown in Figure 4(a), the numbers of WBC in mice were significantly increased by the bacterial infection $(P<0.05)$. Although the data was still above the normal level, positive drugs and SMP significantly reversed these alterations induced by $E$. coli and $S$. aureus $(P<0.05)$.

The changes in IL- 1, IL- 6, TNF- $\alpha$, and IgM concentrations in serum samples of each group were illustrated in Figures $4(\mathrm{~b})-4(\mathrm{e})$. The range of references provided by the kit company is as follows: IL-1, 85.6-124.65 pg/mL; IL-6, 45.85-92.75 pg/mL; IgM, 1000.05-2106.25 $\mu \mathrm{g} / \mathrm{mL} ;$ TNF- $\alpha$ : 205.5-345.75 pg/mL.

The expressions of IL-1, IL-6, and TNF- $\alpha$ in serum were significantly upregulated in bacterial infection group compared with the control $(P<0.05)$. The treatment of positive drugs decreased the levels of these expressions remarkably relative to the $E$. coli and $S$. aureus group $(P<0.05)$ and brought these indicators closer to normal values (range) than those of SMP pretreatment. Although SMP did not significantly reduce the expression of these inflammatory factors as positive drugs in all intervention groups, it can be seen that SMP has a certain anti-inflammatory ability (Figures 4(b)-4(d)).

When the mice were infected with bacteria, the IgM expressions raised compared to the control group $(P<0.05)$. After intervened with SMP, the IgM expressions were increased significantly compared to the infected and 2 positive drug groups $(P<0.05)$ (Figures $4(\mathrm{e})$ ).

Bacteria enter and multiply in the body, triggering the body's inflammatory response and immune response. IL-1, IL-6, and TNF- $\alpha$ are important proinflammatory cytokines and inflammatory mediators, which are critical in the inflammation-associated and immunization-associated response [26-29]. The above cytokines are mainly secreted by white blood cells, so the concentration of cytokines that are secreted is related to the number of white blood cells. Our results also confirm this phenomenon. The $\mathrm{WBC}$ value of the SMP pretreatment group was significantly higher than that of the control group $(P<0.05)$ and beyond the normal range; as a result, the content of other inflammatory factors was also at a higher level. This suggests that the body is still in an inflammatory state. In this respect, positive drugs (amikacin and vancomycin) worked well because they can inhibit the pathogen directly. IgM mainly exists in the blood of organisms and is also the earliest antibody in the initial humoral immune response, which plays a vital role in the immune response. Studies have shown that the levels of IL-1, IL-6, TNF- $\alpha$, and IgM in mice increased significantly in the acute stage of $E$. coli and S. aureus infection [30-33]. Our test results are consistent with those reported above. The body responds to infection by secreting a variety of substances that regulate immune and inflammatory responses, which 
TABLE 2: Number of survivors and mortality data of each group.

\begin{tabular}{lccccccc}
\hline Group & Control & E. coli & E. coli + amikacin & E. coli+SMP & S. aureus & S. aureus + vancomycin & S. aureus + SMP \\
\hline Total & 24 & 24 & 24 & 24 & 24 & 24 & 24 \\
Deaths & 0 & 13 & 4 & 9 & 14 & 3 & 7 \\
Survivors & 24 & 11 & 20 & 15 & 10 & 22 & 17 \\
Mortality & $0 \%$ & $54.2 \%^{\mathrm{a}}$ & $16.7 \%^{\mathrm{b}}$ & $37.5 \%^{\mathrm{ab}}$ & $58.3 \%^{\mathrm{A}}$ & $12.5 \%^{\mathrm{B}}$ & $29.2 \%{ }^{\mathrm{AB}}$ \\
\hline
\end{tabular}

Note: line data marked without the same superscripts (a-b or A-B) differ significantly $(P<0.05)$.

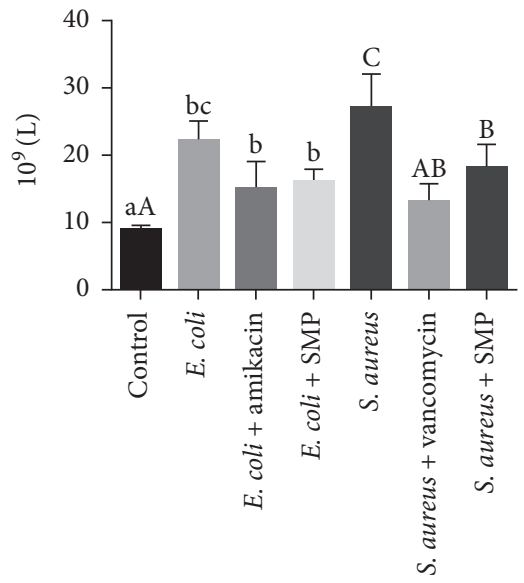

(a)

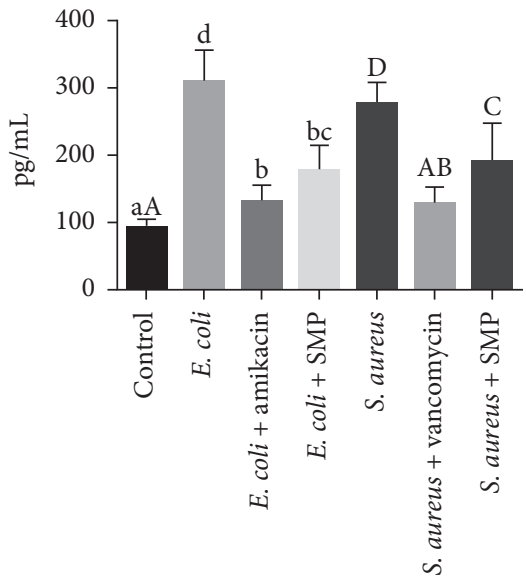

(b)

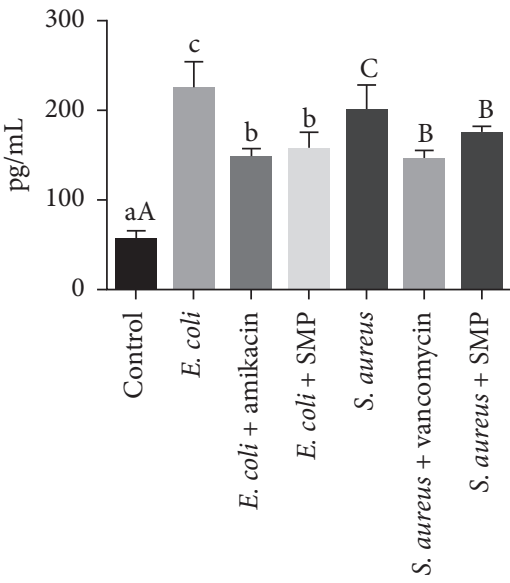

(c)

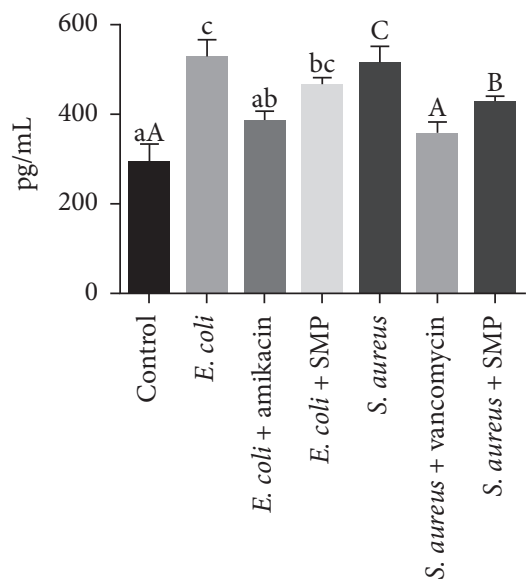

(d)

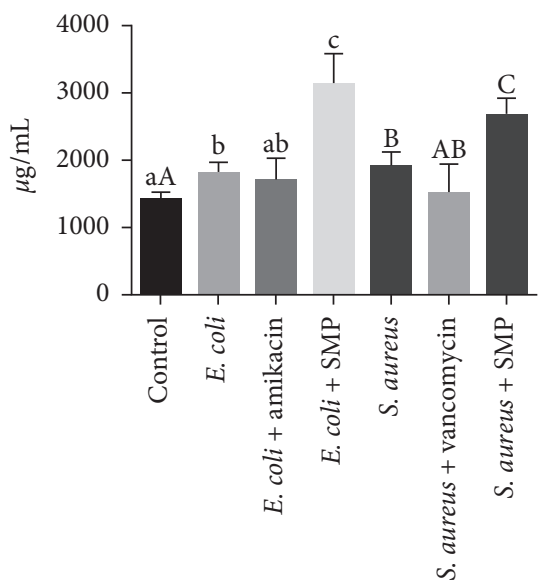

(e)

Figure 4: The WBC (a) and production of serum IL-1 (b), IL-6 (c), TNF- $\alpha$ (d), and IgM (e) of mice in different groups. Control: uninfected and without intervention. E. coli or S. aureus: infected with E. coli or S. aureus and without intervention. E. coli + amikacin or S. aureus + vancomycin: as positive controls, mice infected with $E$. coli or $S$. aureus were subcutaneously injected with amikacin or vancomycin at 5 hours after infection, respectively. E. coli + SMP or S. aureus + SMP: after treated with SMP for 7 days, mice were infected with E. coli or S. aureus. All the bold samples were taken on day 9. Values in a column with different superscripts (a-d, or A-D) were significantly different $(P<0.05)$.

requires a lot of energy in these processes. SMP is a polysaccharide, a type of sugar that provides energy to the body when taken in it. At the same time, SMP can reduce the level of the inflammatory response by downregulating WBC, IL1, IL-6, and TNF- $\alpha$; meanwhile, it can improve immune function by promoting the expression of IgM even though SMP has no direct bacteriostatic activity. Moreover, SMP has a certain antioxidant effect and it is difficult to study the whole mechanism through certain means of in vivo research. According to ancient books, Semiaquilegia adoxoides (DC.)
Makino can cure acute infectious diseases caused by $S$. aureus and E. coli in clinical infection and the results of this experiment confirm this statement in some way. This trial is a preliminary study, and we plan to take further research on the biological activity of SMP in the future.

\section{Conclusions}

We concluded that polysaccharide from Semiaquilegia adoxoides (DC.) Makino (SMP) was a furanose and mainly 
composed of glucose $(60.3 \%)$ and, at the same time, it has a potential antioxidant effect. SMP also had no antibacterial activity but raised the IgM and reduced WBC, IL-1, IL-6, and TNF- $\alpha$ to upregulate immunity and downregulate inflammation, leading to lower mortality of mice infected with $S$. aureus and E. coli. This work indicated that SMP could be explored as a promising antibacterial agent in the food and pharmaceutical industries.

\section{Data Availability}

The data used to support the findings of this study are available from the corresponding author upon request.

\section{Conflicts of Interest}

The authors declare that they have no conflicts of interest.

\section{Authors' Contributions}

Yunqiao Yang, Lei Guo, Kinza Tariq, and Weiyu Zhang contributed equally to this work.

\section{Acknowledgments}

This work was supported by the Science and Technology Major Project of Guangxi (China) (AA17204057) and the National Natural Science Foundation of China (31760746, 31460675).

\section{References}

[1] D. J. Diekema and Group TSP, "Survey of infections due to Staphylococcus species: frequency of occurrence and antimicrobial susceptibility of isolates collected in the United States, Canada, Latin America, Europe, and the Western Pacific region for the SENTRY Antimicrobial Surveillance," Clinical Infectious Diseases An Official Publication of the Infectious Diseases Society of America, vol. 32, no. 2, p. S114, 2001.

[2] S. P. A. Wahyuningsih, M. Pramudya, I. P. Putri et al., "Crude polysaccharides from okra pods (Abelmoschus esculentus) grown in Indonesia enhance the immune response due to bacterial infection," Advances in Pharmacological Sciences, vol. 2018, Article ID 8505383, 7 pages, 2018.

[3] Y. Su, Z. Zhang, and C. Guo, "A new nitroethylphenolic glycoside from semiaquilegia adoxoides," Fitoterapia, vol. 75, no. 3-4, pp. 420-422, 2004.

[4] B. Liang, W. Wei, J. Wang et al., "Protective effects of Semiaquilegia adoxoides n-butanol extract against hydrogen peroxide-induced oxidative stress in human lens epithelial cells," Pharmaceutical Biology, vol. 54, no. 9, pp. 1656-1663, 2016.

[5] S. P. Duan, C. L. Jin, J. Hao et al., "A study on the inhibitory effect of Radix Semiaquilegiae extract on human hepatoma HEPG-2 and SMMC-7721 cells," African journal of traditional, complementary, and alternative medicines, vol. 10, no. 5, pp. 336-340, 2013.

[6] C. L. Zhi, Wl Chen, and G. Pavilion, Flora Reipublicae Populais Sinicae, vol. 27, p. 486, 1979.

[7] G. W. Chen, Y. H. Lin, C. H. Lin, and H. C. Jen, “Antibacterial activity of emulsified pomelo (citrus grandis osbeck) peel oil and water-soluble chitosan on Staphylococcus aureus and Escherichia coli," Molecules, vol. 23, 4 pages, 2018.

[8] L. L. Shao, J. Xu, M. J. Shi et al., "Preparation, antioxidant and antimicrobial evaluation of hydroxamated degraded polysaccharides from Enteromorpha prolifera," Food Chemistry, vol. 237, pp. 481-487, 2017.

[9] Y. Chen, X. Jiang, H. Xie, X. Li, and L. Shi, "Structural characterization and antitumor activity of a polysaccharide from Ramulus mori," Carbohydrate Polymers, vol. 190, pp. 232-239, 2018.

[10] A. Suszko and B. Obminska-Mrukowicz, "Effects of polysaccharide fractions isolated from Caltha palustris L. on the activity of phagocytic cells \& humoral immune response in mice with collagen-induced arthritis: a comparison with methotrexate," The Indian Journal of Medical Research, vol. 145, no. 2, pp. 229-236, 2017.

[11] A. M. Staub, "Removal of proteins-sevag method," Methods in Carbohydrate Chemistry, vol. 5, pp. 5-6, 1965.

[12] M. Ennaifer, T. Bouzaiene, M. Chouaibi, and M. Hamdi, "Pelargonium graveolens aqueous decoction: a new water-soluble polysaccharide and antioxidant-rich extract," BioMed Research International, vol. 2018, Article ID 2691513, 11 pages, 2018.

[13] C. C. Wang, S. C. Chang, B. S. Inbaraj, and B. H. Chen, "Isolation of carotenoids, flavonoids and polysaccharides from Lycium barbarum L. and evaluation of antioxidant activity," Food Chemistry, vol. 120, no. 1, pp. 184-192, 2010.

[14] Y. Y. Xie, M. S. Liu, P. P. Hu et al., "Synthesis, physicochemical properties, and antimicrobial evaluation of a new series of iron (III) hexadentate chelators," Medicinal Chemistry Research, vol. 22, no. 5, pp. 2351-2359, 2013.

[15] H. Jian, F. Qiao, J. Chen, and N. He, "Physicochemical characterisation of polysaccharides from the seeds and leaves of miracle fruit (Synsepalum dulcificum) and their antioxidant and $\alpha$-glucosidase inhibitory activities in vitro," Journal of Chemistry, vol. 2017, Article ID 8948639, 9 pages, 2017.

[16] K. Masisi, T. Beta, and M. H. Moghadasian, "Antioxidant properties of diverse cereal grains: a review on in vitro and in vivo studies," Food Chemistry, vol. 196, pp. 90-97, 2016.

[17] Q. Yuan, Y. Xie, W. Wang et al., "Extraction optimization, characterization and antioxidant activity in vitro of polysaccharides from mulberry (Morus alba L.) leaves," Carbohydrate Polymers, vol. 128, pp. 52-62, 2015.

[18] H. Y. Yang, D. W. Wang, J. Deng et al., "Activity and structural characteristics of peach gum exudates," International Journal of Polymer Science, vol. 2018, Article ID 4593735, 5 pages, 2018.

[19] S. Ananthi, H. R. Raghavendran, A. G. Sunil et al., "In vitro antioxidant and in vivo anti-inflammatory potential of crude polysaccharide from Turbinaria ornata (Marine Brown Alga)," Food and Chemical Toxicology, vol. 48, no. 1, pp. 187-192, 2010.

[20] Z. Ahmed, Y. Wang, N. Anjum et al., "Characterization of new exopolysaccharides produced by coculturing of $\mathrm{L}$. kefiranofaciens with yoghurt strains," International Journal of Biological Macromolecules, vol. 59, pp. 377-383, 2013.

[21] B. Chabbert, A. Habrant, M. Herbaut et al., "Action of lytic polysaccharide monooxygenase on plant tissue is governed by cellular type," Scientific Reports, vol. 7, no. 1, p. 17792, 2017.

[22] C. Y. Liang and R. H. Marchessault, "Infrared spectra of crystalline polysaccharides. II. Native celluloses in the region from 640 to $1700 \mathrm{~cm}^{-1}$," Journal of Polymer Science, vol. 39, no. 135 , pp. 269-278, 1959.

[23] C. Zhao, Z. Liao, X. Wu et al., "Isolation, purification, and structural features of a polysaccharide from Phellinus linteus 
and its hypoglycemic effect in alloxan-induced diabetic mice," Journal of Food Science, vol. 79, no. 5, pp. H1002-H1010, 2014.

[24] W. N. Beavers and E. P. Skaar, "Neutrophil-generated oxidative stress and protein damage in Staphylococcus aureus," Pathogens and Disease, vol. 74, p. 6, 2016.

[25] K. Dutta, D. Nandi, and B. Bishayi, "Repeated systemic Escherichia coli infection enhances anti-oxidant response in hypercholesterolemic mice inducing cardiovascular inflammation," Inflammation, vol. 32, no. 2, pp. 89-98, 2009.

[26] Y. Zhang, W. Kong, and J. Jiang, "Prevention and treatment of cancer targeting chronic inflammation: research progress, potential agents, clinical studies and mechanisms," Science China Life Sciences, vol. 60, no. 6, pp. 601-616, 2017.

[27] A. M. Johnson, S. P. Kurti, J. R. Smith, S. K. Rosenkranz, and C. A. Harms, "Effects of an acute bout of moderate-intensity exercise on postprandial lipemia and airway inflammation," Applied Physiology, Nutrition, and Metabolism, vol. 41, no. 3, pp. 284-291, 2016.

[28] A. Matsuda, K. Motomura, H. Saito, K. Matsumoto, and J. Abe, "High-dose IgG completely inhibited TNF-alpha-induced, but not IL-1 beta-induced, G-CSF expression by human coronary artery endothelial cells," Circulation, vol. 131, 2015.

[29] J. Zschuentzsch, C. Weller, Y. X. Zhang et al., "Human IgG but not liposomal prednisolone improves the early clinical course of mdx mice as model for Duchenne muscular dystrophy," Journal of Neuroimmunology, vol. 253, no. 1-2, pp. 177-178, 2012.

[30] J. Duan, Y. Xie, J. Yang et al., "Variation of circulating inflammatory mediators in Staphylococcus aureus and Escherichia coli bloodstream infection," Medical Science Monitor, vol. 22, pp. 161-171, 2016.

[31] C. Chen, Q. Chen, L. Li et al., "Effects of recombinant fusion protein interleukin-18 on expression of immune-inflammatory factors in mice infected with Staphylococcus aureus," Zhongguo Dang Dai Er Ke Za Zhi, vol. 19, no. 6, pp. 705-711, 2017.

[32] A. A. Durgaryan, M. B. Matevosyan, T. Y. Seferyan et al., "The protective and immunomodulatory effects of hypothalamic proline-rich polypeptide galarmin against methicillin-resistant Staphylococcus aureus infection in mice," European Journal of Clinical Microbiology \& Infectious Diseases, vol. 31, no. 9, pp. 2153-2165, 2012.

[33] S. Sasaki, Y. Tagawa, Y. Iwakura, and A. Nakane, "The role of gamma interferon in acquired host resistance against Staphylococcus aureus infection in mice," FEMS Immunology \& Medical Microbiology, vol. 46, no. 3, pp. 367-374, 2006. 